\title{
Superior Vena Cava Syndrome and Multiple Venous Thrombosis in a Patient with B Cell Lymphoma
}

\author{
Mehmet Zahid Kocak, Gulali Aktas, Edip Erkus, Burcin Atak, Tuba Duman, Haluk Savli \\ Abant Izzet Baysal University Hospital, Department of Internal Medicine, Bolu, Turkey
}

\begin{abstract}
Background: Superior vena cava syndrome (SVCS) develops due to external mechanical pressure of superior vena cava (SVC) by a mass lesion or by an enlarged lymph node, tumor invasion of the vessel wall, or venous thrombosis resulting in intraluminal obstruction. Approximately 3,9\% of lymphomas are complicated with SVCS. This rate reaches to $7 \%$ in diffuse large B cell lymphoma. The objective of this article was to describe a case report of a young woman with a diffuse large B cell lymphoma, complicated with pericardial-pleural effusion and SVCS.

Methods: A 25 year old woman referred to the Internal Medicine Clinic of Abant Izzet Baysal University Hospital with complaints of bloating in the neck and both arms. She had chest pain, dyspnea, cough, and epigastric discomfort for 10 days. A thoracic magnetic resonance imaging (MRI) test and pathological assessment were carried out.

Results: A mediastinal mass $64 \times 112 \times 82 \mathrm{~mm}$ in size, displaced the heart and main mediastinal structures to posterior, was detected by thoracic magnetic resonance imaging (MRI) test. The result of the pathological assessment of the biopsy specimen revealed large B cell lymphoma, stained strongly and diffusely with CD20 and bcl-2. She was referred to the hematology unit and doing well after a chemotherapy.

Conclusions: Diagnosis of SVCS requires high level of clinical suspicion, detailed and complete physical examination. Moreover, SVCS should be kept in mind in the differential diagnosis of patients presented with edema in the neck and upper extremities.
\end{abstract}

Keywords: Lymphoma, mediastinal mass, superior vena cava syndrome

\section{Introduction}

Superior vena cava syndrome (SVCS) develops due to external mechanical pressure of superior vena cava (SVC) by a mass lesion or by an enlarged lymph node, tumor invasion of the vessel wall, or venous thrombosis resulting in intraluminal obstruction. ${ }^{1,2}$ Despite symptomatic relief is the rule in treatment of the patients with $\mathrm{SVCS}^{3}$, cerebral edema may develop. ${ }^{4}$

The underlying etiologic cause is malignancy in about $60-90 \%$ of SVCS cases. Bronchogenic carcinoma remains the most common malignant etiology in SVCS, but lymphoma and germ cell tumors follow that clinical entity. ${ }^{1}$ On the other hand, iatrogenic causes may also promote superior vena cava syndrome. $^{5}$ Generally, $3.9 \%$ of lymphomas complicate with SVCS. This rate reaches to $7 \%$ in diffuse large B cell lymphoma and $21 \%$ in lymphoblastic lymphoma. ${ }^{6}$

This article decribed a case report of a 25-year-old woman with a diffuse large B cell lymphoma, complicated with pericardialpleural effusion and SVCS.

\section{Case}

A 25-year-old woman referred to the Internal Medicine Clinic of Abant Izzet Baysal University Hospital with complaints of bloating in the neck and both arms, recently. She also had chest pain, dyspnea, cough, and 
epigastric discomfort for 10 days. Although she had a history of cholecystectomy due to cholelithiasis a month ago, she did not complain of night sweats and $35 \mathrm{~kg}$ weight loss within two years. Additionally, she was not using medications regularly. The progressive dyspnea and edema in neck and arms lead to a preliminary diagnosis of SVCS.

A physical examination revealed the patient's arterial blood pressure was 120/90 $\mathrm{mmHg}$, heart rate was 115 beats per minute, body temperature was $36.9^{\circ}$ Celsius and respiratory rate was 20 per minute. The patient was comfortable only at sitting position. Moreover, her face was plethoric and the enlarged neck veins were notable along with the diffuse bulging in the neck and edema in both arms. However, lymphadenopathy and splenomegaly were not detected.

Furthermore, blood test results were as follows: hemoglobin: $10.2 \mathrm{~g} / \mathrm{dl}$, hematocrit: $32 \%$, white blood cell count: $9,850 / \mathrm{mm}^{3}$, platelet count: $412,000 / \mathrm{mm}^{3}$, erythrocyte sedimentation rate: $69 \mathrm{~mm} /$ hour, lactate dehydrogenase: $911 \mathrm{U} / \mathrm{l}$, uric acid: $4.8 \mathrm{mg} /$ dl. The rest of the serum biochemistry was normal. Viral serology, including Ebstein-Barr virus, was negative.

Furthermore, multiple lymphadenopathies of which the largest sized was $6 \mathrm{~mm}$ and sub-acute thrombi in left jugular vein were detected in the neck sonography. The Doppler ultrasonography of upper extremities revealed sub-acute thrombi at the left axillary, brachial and cephalic veins.

Moreover, a portable echocardiogram revealed a pericardial effusion and a chest x-ray signed enlarged mediastinum. Besides bilateral pleural and pericardial effusions, a heterogeneous malignant mass at the anterior mediastinum, $64 \times 112 \times 82 \mathrm{~mm}$ in size, displaced the heart and main mediastinal structures to posterior was detected by the thoracic magnetic resonance imaging (MRI) test. The mass surrounded the circumference of ascending aorta by 270 degrees, pulmonary trunk and its branches by 180 degrees, and completely surrounded the circumferences of bilateral brachiocephalic veins and superior vena cava (figure 1). Then, a transthoracic biopsy was performed.

Additionally, aortocaval and para-aortic lymph nodes, of which the largest was $7.1 \mathrm{~mm}$ were visualized by the abdominal tomography. No hepatomegaly or splenomegaly was noted.

Based on these, Enoxaparin $60 \mathrm{mg}$ twice a day was prescribed. Dexamethasone $4 \mathrm{mg}$ four times a day was initiated due to progressive dyspnea and upper extremity edema. Dyspnea and cough were ameliorated at the $2^{\text {nd }}$ day of the treatment. While, pathological assessment of the biopsy specimen revealed a large B cell lymphoma, stained strongly and diffusely with CD20 and bcl-2.

On the $5^{\text {th }}$ day of treatment, the patient was doing well; her clinical signs and symptoms were improved. So she was referred to a hematology center for appropriate chemotherapy treatment.

\section{Discussions}

The main finding of the present report was that superior vena cava syndrome could be

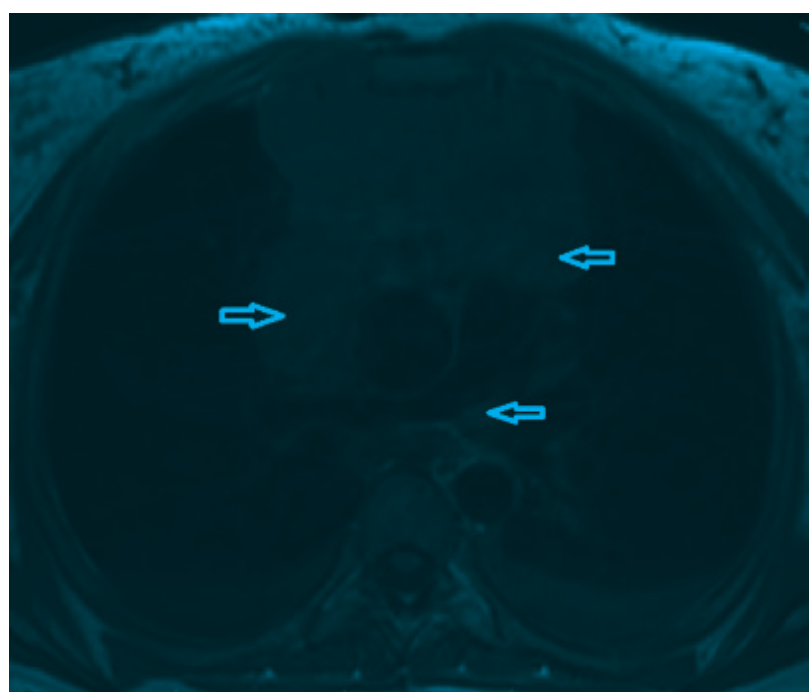

Figure 1 Mediastinal Lymphadenopathy in Magnetic Resonance Imaging 
caused by lymphoma in young age despite the lack of palpable lymphadenopathies. Careful history review, physical examination and imaging studies were needed to establish the underlying etiology in this syndrome.

The superior vena cava syndrome was first described by William Hunter in $1757 .{ }^{7}$ It often poses medical emergency. Approximately 60$90 \%$ of SVCS cases are caused by malignancy, which increases the incidence of thrombosisassociated SVCS due to increased venous thrombosis in malignancies. ${ }^{1}$ Patients with SVCS usually complain of cough, shortness of breath, voice disturbance and stridor. ${ }^{8,9}$ Severity of the symptoms in SVCS is depended on the rate of progression, the degree of obstruction, and the association between congestion and azygos vein. ${ }^{1}$ In this case report, the patient was presented with chest pain, dyspnea, cough, facial plethora and edema in both upper extremities and in the neck. In addition to these findings, bilateral pleural and pericardial effusions were detected in our patient.

The enlarged paratracheal lymph nodes, lymphomas and thymomas located in the mediastinum or anterior mediastinum caused SVCS via the external compression of the superior vena cava. However, bronchogenic carcinoma has the highest association with SVCS development. ${ }^{8,9} \mathrm{Yu}$ et al. ${ }^{10}$ classified SVCS as asymptomatic, mild, moderate, serious, life-threatening, and fatal according to the symptoms and findings of patients and concluded that the most common form of SVCS is moderate SVCS (50\%) and least common is fatal SVCS $(<1 \%)$. According to this classification, our phenomenon is in accordance with the moderate class SVCS.

The contrast-enhanced thoracic computed tomography is the most useful diagnostic method for evaluating. ${ }^{1}$ In patients with contrast allergy, thoracic MRI is a good alternative with an equal sensitivity. ${ }^{1}$ Biopsy is needed to confirm the underlying cause of SVCS in patients presented with undiagnosed mass.

Although the younger age of the patient along with pericardial and pleural effusions and multiple sub-acute venous thrombi suggested the possibility of mediastinal large B cell lymphoma, we detected diffuse $B$ cell lymphoma in our case. According to the World Health Organization (WHO) classification, MBBHL (mature large B cell lymphoma) is classified under the title of diffuse large B-cell lymphoma (DBBHL) and the average age of onset is between $35-40$ years. The MBBHL is differentiated from DBBHL at the molecular level by the absence of Bcl-2. ${ }^{11}$ On the other hand, presentation with SVCS is a rare condition in lymphomas, advanced cases may present this syndrome as seen in our patient.

The SVCS treatment is largely dependent on the underlying cause. Supportive and symptomatic treatments include corticosteroids, diuretics and elevation of head of the bed. However, there is no evidencebased validation for any of these approaches that they are curative. ${ }^{2}$ Since lymphomas are steroid-sensitive malignancies, the steroid therapy provided symptomatic relief in the present case. The present patient responded well to the standard chemotherapy for diffuse large B cell lymphoma.

In conclusion, diagnosis of SVCS requires high level of clinical suspicion, detailed and complete physical examination. SVCS should be kept in mind in the differential diagnosis of the patient whom is presented with edema in neck and upper extremities.

\section{References}

1. Owens Cd, Rapp JH, Gasper WJ, Johnson MD. Superior vena caval obstruction. Blood vessels and lymphatic disorders. In: Papadakis MA, McPhee SJ, editors. Current medical diagnosis and treatment (Lange). 54th ed. San Fransisco: McGraw Hill Education; 2015. p. 481-2.

2. Shenoy S, Shetty S, Lankala S, Anwer F, Yeager A, Adigopula S. Cardiovascular oncologic emergencies. Cardiology. 2017;138(3):147-58.

3. Friedman T, Quencer KB, Kishore SA, Winokur RS, Madoff DC. Malignant venous obstruction: superior vena cava syndrome and beyond. Semin Intervent Radiol. 2017;34(4):398-408 .

4. Talapatra K, Panda S, Goyle S, Bhadra K, Mistry R. Superior vena cava syndrome: A radiation oncologist's perspective. J Can Res Ther. 2016;12(2):515-9.

5. Thapa S, Terry PB, Kamdar BB. Hemodialysis catheter-associated superior vena cava syndrome and pulmonary embolism: a case report and review of the literature. BMC Res Notes. 2016;9:233.

6. Ferhanoğlu B. Diffuse Large B cell Lymphomas- Clinical findings and Treatment. 2006. [cited 2018 January 28]. Available from: http://www.thd.org.tr/ thdData/userfiles/file/diffuz_buyuk_b. pdf.)

7. Stajnic M, Canji T, Panić G, Tomić N, Jelkić 
N, Kovacević B. The superior vena cava syndrome as a manifestation of dissection of the ascending aorta. Med Pregl. 2001;54(7-8):380-2.

8. Lepper PM, Ott SR, Hoppe H, Schumann C, Stammberger U, Bugalho A, et al. Superior vena cava syndrome in thoracic malignancies. Respir Care. 2011;56(5):653-66.

9. Wan JF, Bezjak A. Superior vena cava syndrome. Emerg Med Clin North Am. 2009;27(2):243-55.
10. Yu JB, Wilson LD, Detterbeck FC. Superior vena cava syndrome-a proposed classification system and algorithm for management. J Thorac Oncol. 2008;3(8):811-4.

11. Arlindo EM, Marcondes NA, Fernandes FB, Faulhaber GAM. Quantitative flow cytometric evaluation of CD200, CD123, CD43 and CD52 as a tool for the differential diagnosis of mature B-cell neoplasms. Rev Bras Hematol Hemoter. 2017;39(3):252-8. 